\section{KREATIF}

Jurnal Ilmiah

Prodi Manaiemen Universitas Pamulang
Pamulang ISSN : $2339-0689$, E-ISSN : 2406-8616

J. KREATIF, Vol. 7, No. 2, Desember 2019 (Halaman 59-72)

Tersedia Online di : http://openjournal.unpam.ac.id/index.php/kreatif

\title{
ANALISIS PENGARUH GAYA KEPEMIMPINAN, BUDAYA ORGANISASI DAN KOMPENSASI TERHADAP SEMANGAT KERJA PEGAWAI PADA PT INDONESIA COMNETS PLUS DIVISI CONTACT CENTER PLN 123 SITE JAKARTA
}

\author{
Nariah \\ Program Studi Manajemen \\ Dosen Universitas Pamulang \\ dosen02459@unpam.ac.id
}

\begin{abstract}
ABSTRAK
Tujuan penelitian ini untuk mengetahui pengaruh secara parsial maupun simultan Gaya Kepemimpinan, Budaya Organisasi Dan Kompensasi Terhadap Semangat Kerja Pegawai Pada PT Indonesia Comnets Plus Divisi Contact Center Pln 123 Site Jakarta.

Jenis penelitian ini adalah asosiatif dengan pendekatan deskriptif dan kuantitatif. Adapun populasi dalam penelitian ini sebanyak 296 responden dan menggunakan teknik sampling random tidak berstrata dengan teknik slovin untuk menentukan jumlah sampel sehingga diperoleh sampel sebanyak 170 responden. Adapun alat analisis menggunakan analisis regresi linear berganda dengan bantuan Software SPSS 24.

Hasil penelitian ini menunjukkan bahwa, secara parsial terdapat Pengaruh antara Gaya Kepemimpinan $\left(\mathrm{X}_{1}\right)$ Terhadap Semangat Kerja $(\mathrm{Y})$ dengan nilai $t_{\text {hitung }} 2,035>\mathrm{t}$ table 1,974. Secara Parsial Terdapat Pengaruh antara Budaya Organisasi $\left(\mathrm{X}_{2}\right)$ Terhadap Semangat Kerja (Y) dengan nilai $t_{\text {hitung }} 3,878>t$ table 1,974. Secara Parsial antara Kompensasi $\left(X_{3}\right)$ Terhadap Semangat Kerja (Y) dengan nilai $t_{\text {hitung }}$ 2,991 > t table 1,974. Terdapat Pengaruh Secara Simultan Antara Gaya Kepemimpinan $\left(\mathrm{X}_{1}\right)$, Budaya Organisasi $\left(\mathrm{X}_{2}\right)$ dan Kompensasi $\left(\mathrm{X}_{3}\right)$ Terhadap Semangat Kerja (Y) dengan nilai $F_{\text {hitung }} 63,567>F_{\text {tabel }} 2,66$. Kontribusi ketiga variabel bebas $\mathrm{R}^{2}$ sebesar 53,5\% terhadap Semangat Kerja (Y) dan sisanya sebesar 46,5\% dipengaruhi oleh faktor lainnya
\end{abstract}

Kata Kunci : Gaya Kepemimpinan, Budaya Organisasi, Kompensasi Dan Semangat Kerja

\section{ABSTRACT}

The purpose of this study to determine the effect of partial or simultaneous between the Style of Leadership, Organizational Culture And Compensation Against Work Spirit Employees At PT Indonesia Comnets Plus Contact Center Division Pln 123 Site Jakarta.

This research type is associative with descriptive and quantitative approach. The population in this study as many as 296 respondents and using a random sampling technique is not stratified with slovin technique to determine the number of samples so that obtained a sample of 170 respondents. The analytical tool uses multiple linear regression analysis with the help of SPSS 24 Software.

The results of this study indicate that, partially, there is an Influence between the Leadership Style (X1) on Work Spirit (Y) with a 
tcount of $2.035>t$ table 1.974. Partially There Is An Influence Between Organizational Culture (X2) On Work Morale (Y) with a tcount of 3.878 > t table 1.974. Partially between Compensation (X3) Against Work Morale (Y) with a value of $2.991>t$ table 1.974. There Are Simultaneous Influences Between Leadership Style (X1), Organizational Culture (X2) and Compensation (X3) Against Work Spirit (Y) with a value of Fcount $63.567>$ Ftable 2.66. The contribution of the three independent variables $R 2$ was $53.5 \%$ towards Work Morale $(Y)$ and the remaining $46.5 \%$ was influenced by other factors

Keywords: Leadership Style, Organizational Culture, Compensation and Moral

\section{PENDAHULUAN}

\section{A. Latar Belakang}

Kondisi perekonomian dan nilai tukar Indonesia sekarang ini sedang mengalami penurunan pertumbuhan ekonomi. Dimana tingkat pertumbuhan dari tahun ke tahun masih di bawah 7\%. Selain itu kurs rupiah yang yang cenderung fluktuatif, juga mengakibatkan kenaikan harga yang cukup signifikan, hal ini mengakibatkan tingkat inflasi semakin meninggi. Tidak tercapainya target pertumbuhan ekonomi dan tingkat inflasi yang tidak dapat di tekan, mengakibatkan tidak tercapainya target pemerintah dalam mencapai pertumbuhan ekonomi mengakibatkan terhambatnya perkembangan pembangunan infrastruktur di Indonesia.

Melihat kondisi persaingan saat ini terutama untuk lebih meningkatkan kualitas dan juga lebih meningkatkan kuantitas agar tercapai kebutuhan konsumen. Peran pemimpin sangatlah penting dalam memajukan organisasi khususnya mengelola sumber dayasumber daya yang ada dalam organisasi. Untuk mencapai sasaran perusahaan, karyawan dan masyarakat membutuhkan faktor pendukung dan salah satu nya adalah faktor bahan baku, faktor modal, faktor fasilitas dan alat kerja, serta faktor manusia.

Perihal hubungan komunikasi yang terjadi baik atasan maupun bawahan harus ada saling keterkaitan agar terjalin suatu efektifitas kerja yang baik, sehingga saat mendapatkan masalah kerja dalam suatu perusahaan dapat memecahkan masalah bersama sama tanpa adanya pemahaman yang beda di antara atasan dan bawahan.

Sedangkan Gaya gaya kepemimpinan adalah seseorang yang mampu memberikan arahan dan pengaruh terhadap orang lain dan memiliki wewenang dalam memberikan kebijakan. Kompensasi dimaksudkan untuk memberikan daya rangsangan kepada tenaga kerja agar tenaga kerja mau bekerja dengan sebaik mungkin sesuai dengan kemampuan karyawan tersebut. Kompensasi merupakan motivasi, sedangkan motivasi merupakan dorongan bagi karyawan yang mengakibatkan karyawan mau menyalurkan keterampilannya, serta mendukung perilaku tenaga kerja, agar bekerja sesuai dengan yang diharapkan, memiliki antusias guna mencapai hasil yang baik. Pemberian motivasi baik finansial maupun non finansial sangat penting karena manajemen memberikan pekerjaan kepada para pekerja untuk melakukan dan melaksanakan pekerjaan dengan secara efektif dan efisien serta terfokus kepada tujuan yang diharapkan perusahaan. 
PT. Indonesia Comnets Plus adalah perusahaan yang bergerak di bidang telekomunikasi melalui jaringan listrik. Sebagai anak perusahaan PLN yang harus melayani segala kebutuhan information technology (IT), di tuntut harus memberikan pelayanan yang sebaiknya kepada masyarakat, dan menciptakan hasil kerja yang baik demi pengembangan perusahaan, serta harus mampu membangun dan meningkatkan kinerja sesuai dengan bidang usahanya.

Fenomena masalah yang terjadi saat ini menunjukkan masih rendahnya karyawan dalam mencari solusi guna mengatasi penurunan kinerja. Hal ini disebabkan oleh rendahnya kurang proaktifnya karyawan, sehingga hasil kerja menganggu peningkatan pada produktivitas tugas. Selain itu semangat kerja juga dipengaruhi oleh masing- masing individu itu sendiri, yaitu pada aspek internal karyawan dengan beban tugas yang dihadapinya.

Semangat kerja karyawan secara individu akan memberikan hasil kerja yang positif bagi keseluruhan karyawan dan memberikan masukan yang positif pula terhadap perubahan sikap dan perilaku, yang akan berdampak pada kenaikan hasil kerja. Jadi dapat dismpulkan keberhasilan organisasi tetap kesalahpahaman dikarenakan kurang jelasnya instruksi yang diberikan kepada bawahannya, menyebabkan karyawan kerap mengeluh sehingga timbul kekecewaan bagi karyawan, dan gaya kepemimpinan lainnya yang di anggap terlalu tegas dan otoriter dalam memberikan perintah atau instruksi kepada karyawan dapat membuat karyawan/tenaga kerja merasa takut kurang dalam bekerja.

Budaya organsasi dalam persaingan kerja masih kurang berjalan efektif, selama ini karyawan masih belum termotivasi oleh persaingan kerja sesama karyawan, hal ini dikaraenakan kurangnya pemberian promosi jabatan kepada karyawan yang berprestasi, sehingga karyawan merasa enggan berkompetisi di dalam lingkungan kerja saat ini.

Kompensasi yaitu pemberian finansial maupun nonfinansial yang diberikan kepada tenaga kerja. Berdasarkan pengamatan penulis dan data dari feedback karyawan, masih adanya keluhan-keluhan dari pegawai perihal pemberian kompensasi. Variabel kompensasi menunjukkan masih terdapat kekurang puasan karyawan dalam hal kompensasi. Kurang puasnya karyawan dalam pemberian balas jasa yang diterima, berdampak pada motivasi dan para pekerja karyawan yang akan menurun dan akan mengakibatkan kinerja yang tidak sesuai harapan, sehingga akan menganggu pelayanan kepada pelanggan. Menurut feedack berupa keluhan-keluhan yang diberikan karyawan, tingkat kurang puas karyawan ditunjukkan dengan pemberian kompensasi financial (salary) yang perusahaan berikan kepada karyawan masih kurang. Masih kurangnya gaji yang diberikan saat ini dikarenakan dengan kondisi biaya hidup saat ini, dan kompensasi non financial mengenai peluang promosi jabatan yang di anggap kurang memenuhi harapan karyawan dan bergantung dari tingkat kinerja karyawan yang sangat dipengaruhi oleh proses sikap dan perilaku karyawan dan pimpinan. Seorang pimpinan perusahaan tidak dapat bekerja sendiri tanpa ada integrasi dengan bawahannya. Seorang pemimpin memerlukan bantuan dan kerja sama dari karyawan agar 
mampu melaksanakan hasil kerja sesuai arah dan tujuan dari perusahaan tersebut.

Semangat kerja karyawan dipengaruhi oleh berbagai macam factor diantaranya adalah factor kemampuan mereka sendiri, motivasi, komunikasi, dukungan yang di terima, lingkungan kerja fisik maupun non fisik, pemberian kompensasi, tempat kerja yang nyaman, pengembangan karir, pemberian asuransi kesehatan, keamanan serta keselamatan kerja, hubungan vertical maupun horizontal,.

Banyak temuan yang peneliti dapati, dan temuan tersebut berupa masalah-masalah yang peneliti jadikan dugaan sementara bahwa penyebab tidak baiknya hasil kerja karyawan di divisi Contact Center PLN 123 disebabkan oleh semangat kerja yang menurun. Selain itu menurunnya semangat kerja karyawan juga ditunjukkan dengan absensi yang relatif fluktuatif setiap tahunnya. Penulis menduga karyawan masih kurang memiliki kesadaran dalam mengamalkan nilai-nilai yang ada pada organisasi, terlihat masih tingginya absensi ketidakhadiran karyawan, hal ini akan menyebabkan beban bagi karyawan lainnya dikarenakan kurangnya karyawan dalam melaksanakan pekerjaan, selain itu seringnya karyawan yang tidak hadir membuat terhambatnya proses pekerjaan. Sebagai petugas Contact Center, karyawan di tuntut untuk selalu memberikan solusi bagi pelanggan, apabila masih tingginya angka ketidakhadiran karyawan maka banyak pekerjaan yang tertunda.

Selain itu gaya kepemimpinan, kurangnya komunikasi yang efektif dari pimpinan menyebabkan sering terjadinya juga kesempatan berkarir yang belum berjalan secara efektif.

Berdasarkan temuan awal peneliti, maka peneliti tertarik untuk meneliti lebih jauh mengenai : "Analisis Pengaruh Gaya Kepemimpinan, Budaya Organisasi Dan Kompensasi Terhadap Semangat Kerja Karyawan pada PT Indonesia Comnets Plus Divisi Contact Center PLN 123 Site Jakarta".

\section{B. Perumusan Masalah}

Sesuai judul penelitian dan identifikasi serta pembatasan masalah di atas maka penelitian ini merumuskan masalah sebagai berikut:

1. Apakah terdapat pengaruh secara parsial antara gaya kepemimpinan terhadap semangat kerja karyawan pada PT. Indonesia Comnets Plus Divisi Contact Center PLN 123 Site Jakarta?

2. Apakah terdapat pengaruh secara parsial antara budaya organisasi terhadap semangat kerja karyawan pada PT. Indonesia Comnets Plus Divisi Contact Center PLN 123 Site Jakarta?

3. Apakah terdapat pengaruh secara parsial antara kompensasi terhadap semangat kerja karyawan pada PT. Indonesia Comnets Plus Divisi Contact

Center PLN 123 Site Jakarta?

4. Apakah terdapat pengaruh gaya kepemimpinan, budaya organisasi dan kompensasi terhadap semangat kerja karyawan secara simultan (bersama-sama) pada PT. Indonesia Comnets Plus Divisi Contact Center PLN 123 Site Jakarta ? 


\section{TINJAUAN PUSTAKA}

\section{A. Pengertian Gaya Kepemimpinan}

Kepemimpinan merupakan hal yang penting dan salah satu faktor pendukung yang membuat karyawan memiliki dorongan dan motivasi dalam bekerja. Pemimpin yang baik dan disegani merupakan idaman bagi para karyawan. Pemimpin yang diharapkan bawahan adalah pemimpin yang mampu berbuat adil memberikan motivasi kerjakepada bawahannya.

Seorang pemimpin harus mengetahui perilaku dan karakteristik dari bawahannya, sehingga mampu memberikan keputusan yang bijak dalam memberikan semangat kerja kepada karyawan.

Gaya kepemimpinan adalah sifat, kebiasaan, tempramen, watak dan karakteristik kepribadian yang ada pada diri pemimpin dalam berkomuniasi dan berinteraksi dengan orang lain, Kartono (2008:34)

\section{B. Pengertian Budaya Organisasi}

Budaya menjadi bagian dalam organisasi dan tidak dapat dipisahkan dalam organisasi, karena tidak dapat dipisahkan dari kehidupann manusia. Budaya organisasi adalah seperangkat nilai, keyakinan, dan sikap utama yang diberlakukan di antara anggota organisasi. Darmawan (2013:173).

\section{Pengertian Kompensasi}

Kompensasi merupakan sarana atau dorongan yang diberikan kepada karyawan agar mau bekerja bertindak secara tertentu. Kompensasi merupakan sarana motivasi bagi karyawan, hal ini merupakan pendorong dan semangat karyawan dalam bekerja. apabila kompensasi yang tidak sesuai maka akan menganggui efektifitas kerja suatu karyawan.

Kompensasi adalah semua bentuk finansial maupun non finansial berupa jasa-jasa terwujud dan tunjangan yang di peroleh karyawan sebagai bagian dari hubungan kekaryawanan, Henry Simamora (2014:445)

\section{Pengertian Semangat Kerja}

Motivasi merupakan factor pendorong semangat kerja karyawan, tanpa adanya semangat kerja dalam diri setiap karyawan sulit bagi karyawan untuk meningkatkan semangat kerja dan kinerjanya.

Semangat kerja adalah kemampuan seorang atau sekelompok orang yang bekerjasama dengan giat dan konsekuen dalam mengejar tujuan bersama, Tohardi (2007:427).

Indikator-indikator semangat kerja adalah : disiplin, kepuasan kerja, partisipasi dan kerjasama, Tohardi (2007:433)

\section{METODOLOGI PENLEITIAN}

\section{A. Desain Penelitian}

Jenis penelitian asosiatif adalah penelitian yang memiliki tujuan untuk mengetahui pengaruh atau hubungan antar variabel.

\section{B. Populasi dan Sampel}

\section{Populasi}

Populasi dalam penelitian ini adalah jumlah seluruh karyawan yang akan dijadikan sumber penelitian,

Jumlah populasi karyawan PT. Indonesia Comnets Plus Divisi 
Contact Center PLN 123 Site Jakarta adalah sebanyak 296 orang karyawan.

\section{Sampel}

Sampel yaitu bagian dari jumlah yang terdapat dalam unsur populasi itu sendiri, Sugiyono (2010:118).

Sesuai dengan jumlah populasi maka jumlah sampel penelitian di ambil dengan teknik slovin dengan tingkat kesalahan 5\%:

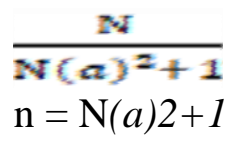

Ket :

$\mathrm{n}=$ ukuran sampel yang dicari $\mathrm{N}=295$ jumlah Populasi

$\alpha=5 \%$ tingkat kesalahan

Jumlah sampel yang akan di cari dengan menggunakan rumus slovin adalah :

$$
\frac{296}{296(0,05)^{2}+1}
$$

$\mathrm{n}=296(0,05) 2+1$

$=170$ orang pegawai

Sesuai dengan perhitungan maka 170 staf karyawan digunakan sebagai sampel

\section{Skala Pengukuran}

Skala pengukuran instrument penelitian dalam penyebaran instrumen menggunakan skala likert. "Skala likert digunakan untuk mengukur opini, persepsi, pendapat sikap, sesorang tentang suatu obyek atau fenomena yang terjadi, Siregar (2014:50)".

Rentang skala pengukuran masing- masing jawaban diberi bobot nilai :

\section{Tabel 3.1}

\begin{tabular}{|c|c|}
\hline \multicolumn{2}{|c|}{ Skala Likert } \\
\hline Alternatif & Bobot \\
\hline Sangat Baik/Sangat Setuju & 5 \\
\hline 2. $\quad$ Baik/Setuju & 4 \\
\hline Netral/Ragu-Ragu & 3 \\
\hline 4. Tidak Baik/Tidak Setuju & 2 \\
\hline $\begin{array}{l}\text { 5. Sangat Tidak Baik/Sangat } \\
\text { Tidak Setuju }\end{array}$ & 1 \\
\hline
\end{tabular}

Sumber : Siregar (2014:50)

\section{Sumber Dan Metode Pengumpulan Data/informasi}

Menurut "Sugiyono (2010:193) pengumpulan data primer dan sumber data skunder" yaitu data primer yaitu sumber data yang langsung memberikan data kepada pengumpul data, sedangkan "Data sekunder adalah data yang didapat secara tidak langsung oleh pengumpul data", Sugiyono (2010:193).

\section{Rancangan Analisis}

\section{a. Uji Kualitas Data}

Uji Validitas Instrumen

Validitas atau kesahihan menunjukkan untuk mengukur apa yang ingin di ukur. Syofian Siregar (2014:75). Rumus uji validitas 
menurut Syofian Siregar (2014:77) adalah :

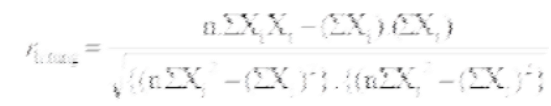

\section{Uji Reliabilitas Instrumen}

Reliabilitas merupakan derajat kehandalan, kepercayaan suatu instrument, yang bertujuan apakah hasil pengukuran instrumen tetap konsisten/handal, jika dilakukan pengukuran dua kali atau lebih, Syofian Siregar (2014:85).

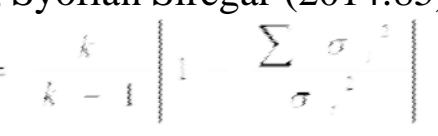

\section{b. Uji Asumsi Klasik}

Ada baberapa uji asumsi klasik, diantaranya :

\section{Uji Normalitas}

Tujuan dilakukan uji normalitas adalah untuk mengetahui apakah populasi data berdistribusi normal atau tidak. Sofiyan Siregar (2014:153)

\section{Uji Heteroskedastisitas}

Menurut Wiratna Sujarweni (2014:31)

heterokedastisitas menguji terjadinya persamaan atau perbedaan varian dari suatu periode pengamatan ke periode pengamatan lain.

\section{Uji Multikolinearitas}

Uji multikolinieritas bertujuan mengetahui variabel independen yang memiliki kemiripan antar variabel independen dalam suatu model.

\section{E. Regresi Linear}

Menurut "Sugiyono (2010:277), regresi, bertujuan, memprediksi dan meramalkan perubahan variabel terikat, bila terjadia perubahan pada variabel bebas". Persamaan regresi yaitu : $Y=a+b_{1} X_{1}+b_{2} X_{2}+b_{3} X_{3}$

\section{F. Uji Hipotesis}

Pengujian hipotesis di uji dengan menggunakan analisis regresi linear berganda, uji parsial dan uji sumultan.

\section{a. Uji t (Parsial)}

Untuk menguji hipotesis parsial (2 variabel), untuk uji parsial digunakan rumus $\mathrm{t}$ test. sedangkan uji t dilakukan untuk menguji kebenaran hipotesis secara parsial Sujarweni (2014:56).

\section{b. Uji F (Simultan)}

Uji $\mathrm{F}$ tes digunakan untuk mengetahui pengaruh secara bersama-sama (simultan).

\section{c. Uji Koefisien Korelasi}

Menurut Syofian Siregar (2014:352) Analis Korelasi untuk mengetahui kekuatan atau hubungan antara dua variabel lebih.

\section{d. Uji Koefisien Determinasi}

Koefisien determinasi (KD) angka yang menyatakan kadar kontribusi atau sumbangan yang diberikan variabel bebas terhadap variabel terikat. Syofian Siregar (2014:338). 


\section{HASIL PENELITIAN DAN PEMBAHASAN}

\section{A. Analisa Deskriptif}

Analisa deskriptif masing-masing variabel dengan menghitung skor instrument dan rata-rata (mean) untuk mengetahui baik tidaknya instrumen menurut para responden dengan mengacu pada rentang skala interval yang telah ditentukan.

\section{Analisa Gaya Kepemimpinan $\left(\mathbf{X}_{1}\right)$}

Hasil skor total instrumen jawaban Gaya Kepemimpinan $\left(\mathrm{X}_{1}\right)$ mendapatkan skor total 6910 dengan nilai mean 40.65 dan mean skors 3.39 nilai ini masuk ke dalam rentang skala skor dengan kategori Cukup Baik. Dengan demikian dapat diketahui bahwa Gaya Kepemimpinan $\left(\mathrm{X}_{1}\right)$ yang diterapkan saat ini sudah cukup baik dalam perannya sebagai pimpinan.

\section{Analisa Budaya Organisasi $\left(\mathbf{X}_{2}\right)$}

Hasil skor total instrumen jawaban Budaya Organisasi $\left(\mathrm{X}_{2}\right)$ mendapatkan skor total 7765 dengan nilai mean 45.68 dan mean skors 3.26 nilai ini masuk ke dalam rentang skala skor dengan kategori Cukup Baik. Dengan demikian dapat diketahui bahwa Budaya Organisasi $\left(\mathrm{X}_{2}\right)$ yang ada saat ini sudah cukup baik.

Analisa Kompensasi $\left(\mathbf{X}_{3}\right)$

Hasil skor total instrumen jawaban Kompensasi $\left(\mathrm{X}_{3}\right)$ mendapatkan skor total 3422 dengan nilai mean 20,13 dan mean skors 2,52 nilai ini masuk ke dalam rentang skala skor dengan kategori Tidak Baik atau rendah. Maka dapat disimpulkan bahwa Kompensasi $\left(\mathrm{X}_{3}\right)$ yang diberikan saat ini belum memenuhi harapan karyawan.

\section{Analisa Semangat Kerja (Y)}

Hasil skor total instrumen jawaban Semangat Kerja (Y) mendapatkan skor total 4749 dengan nilai mean 27,94 dan mean skors 3,49 nilai ini masuk ke dalam rentang skala skor dengan kategori Baik. Maka dapat disimpulkan bahwa Semangat Kerja (Y) pegawai saat ini sudah baik dalam menunjang pekerjaan.

\section{B. Uji Kualitas Data Instrumen}

Kriteria pengambilan keputusan dalam uji validitas dalam penelitian ini adalah :

1. Jika $\mathrm{r}_{\text {hitung }}<\mathrm{r}_{\text {tabel }} 0,151$ dan nilai Sig $>0,05$ maka butir instrument dinyatakan tidak valid

2. Jika $r_{\text {hitung }}>r_{\text {tabel }} 0,151$ dan nilai Sig $<0,05$ maka butir instrument dinyatakan valid

\section{Hasil Validitas Instrumen Gaya Kepemimpinan $\left(\mathbf{X}_{1}\right)$}

Hasil validitas instrument Gaya Kepemimpinan $\left(\mathrm{X}_{1}\right)$ yang terdiri dari 12 pernyataan menunjukkan seluruh $r_{\text {hitung }}>r_{\text {tabel }} 0,151$ dan nilai Sig 0,000 $<0,05$ maka seluruh butir insturmen Gaya Kepemimpinan $\left(\mathrm{X}_{1}\right)$ dinyatakan valid, maka disimpulkan bahwa instrumen yang digunakan sudah tepat dan dapat digunakan sebagi alat ukur.

\section{Hasil Validitas Instrumen Budaya Organisasi $\left(\mathbf{X}_{2}\right)$}


Uji validitas instrument Budaya Organisasi $\left(\mathrm{X}_{2}\right)$ yang terdiri dari 14 pernyataan menunjukkan bahwa, seluruh $r_{\text {hitung }}>r_{\text {tabel }} 0,151$ dan nilai Sig 0,000 $<0,05$ maka diartikan bahwa seluruh butir insturmen Budaya Organisasi $\left(\mathrm{X}_{2}\right)$ dinyatakan valid, maka disimpulkan bahwa instrumen yang digunakan sudah tepat dan dapat digunakan sebagi alat ukur. Hasil Validitas Instrumen Kompensasi $\left(\mathrm{X}_{3}\right)$

Hasil output Software SPSS 24 uji validitas instrumen Kompensasi $\left(\mathrm{X}_{3}\right)$ yang terdiri dari 8 pernyataan menunjukkan bahwa seluruh $r$ hitung $>\mathrm{r} 0,151$ dan nilai Sig $0,000<0,05$ maka

tabel

diartikan bahwa seluruh butir insturmen Kompensasi $\left(\mathrm{X}_{3}\right)$ dinyatakan valid, maka disimpulkan bahwa instrument yang digunakan sudah tepat menjadi alat ukur

\section{Uji Validitas Instrumen Semangat Kerja (Y)}

Hasil output Software SPSS 24 uji validitas instrumen Semangat Kerja (Y) yang terdiri dari 8 pernyataan menunjukkan bahwa seluruh $r_{\text {hitung }}>r_{\text {tabel }}$ 0,151 dan nilai Sig 0,000<0,05 maka diartikan bahwa seluruh butir insturmen Semangat Kerja (Y) dinyatakan valid, maka disimpulkan bahwa instrumen yang digunakan sudah tepat dan dapat digunakan sebagi alat ukur.

\section{Uji Reliabilitas Instrumen}

Kriteria uji reliabilitas Cronbach's Alpha, bila koefisien reliabilitas $\left(r_{11}\right)$ $>0,6$

\section{Tabel}

Hasill Uji Reliabilitas

\begin{tabular}{|l|c|c|c|}
\hline Variabel & Rea & $\begin{array}{l}\text { Kri } \\
\text { teria }\end{array}$ & Ket \\
\hline Gaya Kepemimpinan $\left(\mathrm{X}_{1}\right)$ & 0,954 & 0.6 & Reliabel \\
\hline Budaya Organisasi $\left(\mathrm{X}_{2}\right)$ & 0,917 & 0.6 & Reliabel \\
\hline Kompensasi $\left(\mathrm{X}_{3}\right)$ & 0,887 & 0.6 & Reliabel \\
\hline Semangat Kerja $(\mathrm{Y})$ & 0,795 & 0.6 & Reliabel \\
\hline
\end{tabular}

Melihat output SPSS di atas menunjukkan seluruh koefisien reliabilitas $\left(r_{11}\right)>0,6$ artinya hasil pengukuran instrumen tetap konsisten atau instrumen handal dan dapat di percaya.

\section{Uji Normalitas}

Tabel

Hasil Output Uji Normalitas Kolmogorov- Smirnov

\begin{tabular}{|c|c|c|}
\hline \multicolumn{2}{|l|}{$\mathrm{N}$} & Residual 170 \\
\hline Normal & Mean & .0000000 \\
\hline Parameters $\mathrm{a}, \mathrm{b}$ & $\begin{array}{l}\text { Std. } \\
\text { Deviation }\end{array}$ & 3.23834831 \\
\hline Most Extreme & Absolute & .059 \\
\hline Differences & $\begin{array}{l}\text { Positive } \\
\text { Negative }\end{array}$ & $\begin{array}{r}.049 \\
-.059\end{array}$ \\
\hline $\begin{array}{l}\text { Test Statistic } \\
\text { Asynpmber }\end{array}$ & Hasil Ola & $\begin{array}{lr}\text { ISPSS } 24 \quad .059 \\
.200^{c, d}\end{array}$ \\
\hline
\end{tabular}

Dari hasil uji Normalitas dengan metode kolmogorov-Smirnov diketahui nilai Test Statistic 0,059 dan nilai sig 0,200>0,05 dapat diketahui data residual berdistribusi normal.

\section{Uji Heterokedastisitas}


Berikut hasil output SPSS 24 uji Heterokedastisitas :

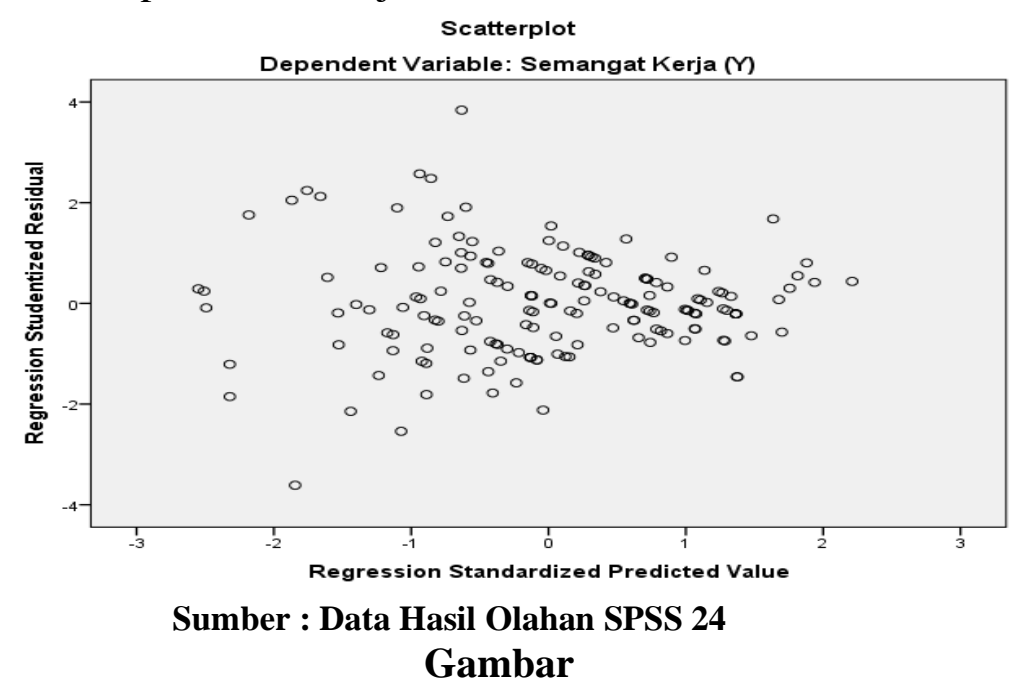

Hasil Output Heterokedastisitas Scatterplot

Dari gambar Scatterplot di atas menunjukkan tidak terjadi

Heteroskedastisitas pada model regresi, dikarenakan titik-titik menyebar dan tidak membentuk pola.

\section{Uji Multikolinearitas}

Kriteria uji multikolinearitas jika Tolerance dan VIF yang dihasilkan di antara 1-10 maka tidak terjadi multikolinieritas. Berikut hasil output SPSS 24 pengujian multikolinieritas :

Tabel

Hasil Output SPSS 24 Pengujian Multikolinieritas

Coefficients $^{\mathrm{a}}$

\begin{tabular}{|l|l|l|l|}
\hline \multicolumn{2}{|l|}{ Model } & Tolerance & VIF \\
\hline 1 & \multicolumn{2}{|l|}{ (Constant) } & \\
\cline { 2 - 4 } & $\begin{array}{l}\text { Gaya Kepemimpinan } \\
\text { (X1) }\end{array}$ & .336 & 2.977 \\
\cline { 2 - 4 } & Budaya Organisasi (X2) & .272 & 3.677 \\
\cline { 2 - 4 } & Kompensasi (X3) & .499 & 2.006 \\
\hline
\end{tabular}

Sumber : Data Hasil Olahan SPSS 24

Dari output di atas menunjukkan bahwa, Tolerance dan VIF berada di rentang 1 - 10. Maka menunjukkan tidak terjadi multikolinieritas sesama varoabel bebas.

C. Uji Regresi Linear Berganda

Berikut output hasil uji regresi linear berganda dengan Software SPSS 24 :

Tabel

Output Hasil Uji Regresi Berganda

Coefficients $^{\text {a }}$

Unstandardized

Coefficients

$\begin{array}{lll}\text { Model } & \text { B } & \text { Std. } \\ \text { Error }\end{array}$




\begin{tabular}{|c|c|c|c|}
\hline \multirow[t]{4}{*}{1} & (Constant) & 11.901 & 1.248 \\
\hline & Gaya Kepemimpinan (X1) & .085 & .042 \\
\hline & Budaya Organisasi (X2) & .199 & .051 \\
\hline & Kompensasi (X3) & .173 & .058 \\
\hline
\end{tabular}

a. Dependent Variable: Semangat Kerja (Y)

Sumber : Data Hasil Olahan SPSS 24

Hasil output SPSS regresi linear berganda adalah $\mathrm{Y}=11,901+0,085$ $\mathrm{X}_{1}+0,199 \mathrm{X}_{2}+0,173 \mathrm{X}_{3}$

Persamaan tersebut bermakna:

a constant a sebesar 11,901 dapat diprediksi/diramalkan, apabila Gaya kepemimpinan $\left(\mathrm{X}_{1}\right)$, Budaya Organisasi $\left(\mathrm{X}_{2}\right)$ dan Kompensasi $\left(\mathrm{X}_{3}\right)$ tidak ada atau $\mathrm{X}=0$ maka nilai Semangat Kerja (Y) adalah sebesar 11,901.

b. Koefisien regresi $\mathrm{b}\left(\mathrm{b}_{1} \mathrm{x}_{1}\right)$ sebesar 0,085 dapat diprediksi/diramalkan bahwa, jika Gaya kepemimpinan $\left(\mathrm{X}_{1}\right)$ meningkat satu-satuan maka akan meningkatkan Semangat Kerja (Y) sebesar 0,085.

c. Koefisien regresi b $\left(\mathrm{b}_{2} \mathrm{X}_{2}\right)$ sebesar 0,199 dapat diprediksi/diramalkan bahwa, jika Budaya Organisasi $\left(\mathrm{X}_{2}\right)$ meningkat satu-satuan maka akan meningkatkan Semangat Kerja (Y) sebesar 0,199.

d. Koefisien regresi $\mathrm{b}\left(\mathrm{b}_{3} \mathrm{X}_{3}\right)$ sebesar 0,173 dapat diprediksi/diramalkan bahwa, jika Kompensasi $\left(\mathrm{X}_{3}\right)$ meningkat satu-satuan maka akan meningkatkan Semangat Kerja (Y) sebesar 0,173.

\section{Uji Hipotesis}

\section{Uji Parsial (Uji t)}

Apabila hasil perhitungan menunjukkan:

a. Jika thitung $>t_{\text {tabel }} 1,974$ dan atau nilai Sig $<0,05$ maka $H_{o}$ di tolak dan $\mathrm{H}_{a}$ di terima

b. Jika $t_{\text {hitung }} \leq t_{\text {tabel }} 1,974$ dan atau nilai $\operatorname{Sig}>0,05$ maka $\mathrm{H}_{\mathrm{o}}$ di terima dan $\mathrm{H}_{\mathrm{a}}$ di tolak

\section{Tabel}

\section{Hasil Output Uji Hipotesis Secara Parsial} Coefficients $^{\mathrm{a}}$

\begin{tabular}{|c|c|c|}
\hline \multicolumn{2}{|c|}{ Model } & \multirow[b]{2}{*}{9.533} \\
\hline 1 & (Constant) & \\
\hline & Gaya Kepemimpinan (X1) & 2.035 \\
\hline & Budaya Organisasi (X2) & 3.878 \\
\hline & Kompensasi (X3) & 2.991 \\
\hline
\end{tabular}

a. Dependent Variable: Semangat Kerja (Y)

\section{Sumber : Data Hasil Olahan SPSS 24}

Melihat table output Coefficients di atas yaitu:

Nilai $t_{\text {hitung }} 2,035>t_{\text {table }} 1,974$ dan nilai Sig 0,043 $<0,05$ maka $\mathrm{H}_{\mathrm{a} 1}$ di terima artinya terdapat pengaruh signifikan antara Gaya Kepemimpinan terhadap Semangat Kerja Pegawai.

Nilai thitung 3,878 $>t_{\text {table }} 1,974$ atau Sig $0,000<0,05$ maka $\mathrm{H}_{\mathrm{a} 2}$ diterima artinya terdapat pengaruh signifikan antara Budaya Organisasi terhadap 
Semangat Kerja Pegawai.

Nilai $t_{\text {hitung }} 2,991>t_{\text {table }} 1,974$ atau Sig $0,003<0,05$ maka $\mathrm{H}_{\mathrm{a} 3}$ diterima maka dapat disimpulkan terdapat pengaruh signifikan antara Kompensasi terhadap Semangat Kerja Pegawai

2. Uji Simultan (Uji F)

Kaidah pengujian signifikasi Uji $\mathrm{F}$ :

a. Jika $\mathrm{F}_{\text {hitung }} \leq \mathrm{F}_{\text {tabel }} 2,66$ dan sig $>0.05, \mathrm{H}_{\mathrm{o4}}$ di terima dan $\mathrm{H}_{\mathrm{a} 4}$ di tolak (Tidak signifikan).

b. Jika $\mathrm{F}_{\text {hitung }}>\mathrm{F}_{\text {tabel }} 2,66$ dan sig $<0.05, \mathrm{H}_{04}$ di tolak dan $\mathrm{H}_{\mathrm{a} 4}$ di terima (signifikan)

Berikut output keluaran SPSS 24 pengujian secara simultan :

\section{Tabel}

Hasil Output Pengujian Hipotesis Secara Simultan

\begin{tabular}{|c|c|c|c|c|c|c|}
\hline \multicolumn{2}{|c|}{ Model } & $\begin{array}{l}\text { Sum of } \\
\text { Squares }\end{array}$ & df & $\begin{array}{l}\text { Mean } \\
\text { Square }\end{array}$ & $\mathrm{F}$ & Sig. \\
\hline \multirow[t]{2}{*}{1} & Regression & 2036.002 & 3 & 678.667 & 63.567 & $.000^{\mathrm{b}}$ \\
\hline & Residual & 1772.286 & 166 & 10.676 & & \\
\hline \multicolumn{2}{|c|}{ Total } & 3808.288 & 169 & & & \\
\hline
\end{tabular}

a. Dependent Variable: Semangat Kerja (Y)

b. Predictors: (Constant), Kompensasi (X3), Gaya Kepemimpinan (X1), Budaya Organisasi (X2) Sumber : Data Hasil Olahan SPSS 24

Nilai $F_{\text {hitung }} 63,567>\quad F_{\text {tabel }} 2,66$ dan sig $\alpha 0,000<0.05$, maka $\mathrm{H}_{\mathrm{o}}$ ditolak dan $\mathrm{H}_{\mathrm{a} 4}$ diterima (signifikan), maka diketahui terdapat pengaruh signifikan secara simultan antara Gaya Kepemimpinan, Budaya Organisasi, dan Kompensasi Terhadap Semangat Kerja Pegawai.

\section{Uji Korelasi dan Determinasi}

Berikut hasil korelasi ganda :

Tabel

Hasil Output Korelasi Ganda Model Summary ${ }^{\mathrm{b}}$

\begin{tabular}{lc|c|c|c|} 
& & & & \multicolumn{1}{c}{$\begin{array}{l}\text { Mtd. Error } \\
\text { of the } \\
\text { Estimate }\end{array}$} \\
Model & $\mathrm{R}$ & $\mathrm{R}$ & $\begin{array}{l}\text { djusted } \mathrm{R} \\
\text { Square }\end{array}$ & \\
\hline 1 & $.731^{\mathrm{a}}$ & .535 & .526 & 3.267 \\
\hline
\end{tabular}

a. Predictors: (Constant), Kompensasi (X3), Gaya Kepemimpinan (X1), Budaya Organisasi (X2)

b. Dependent Variable: Semangat Kerja (Y)

Sumber : Data Hasil Olahan SPSS 24

Nilai korelasi $\mathrm{R}=0,731$ menunjukkan bahwa Gaya Kepemimpinan $\left(\mathrm{X}_{1}\right)$, Budaya Organisasi $\left(\mathrm{X}_{2}\right)$, dan Kompensasi $\left(\mathrm{X}_{3}\right)$ terhadap Semangat Kerja (Y) mempunyai hubungan kuat dengan nilai R 0,731. Dan kontribusi seluruh variabel bebas terhadap Semangat Kerja (Y) $\mathrm{R}^{2}$ sebesar 53,5\% dan sisanya sebesar $46,5 \%$ dipengaruhi oleh faktor lainnya.

\section{PENUTUP}

\section{A. Kesimpulan}

Berikut hasil kesimpulan yang dapat penulis sajikan dari hasil penelitian dan pembahasan :

1. Gaya Kepemimpinan $\left(\mathrm{X}_{1}\right)$ Berpengaruh Secara Parsial yang Terhadap Semangat Kerja (Y). Hal ini ditujukan dengan nilai t hitung 2,035 > t 
table 1,974 dan nilai Sig 0,043

2. $<0,05$.

3. Budaya Organisasi $\left(\mathrm{X}_{2}\right)$ Berpengaruh Secara Parsial yang Positif Dan Signifikan Terhadap Semangat Kerja (Y). Hal ini ditunjukkan dengan nilai $\mathrm{t}_{\text {hitung }} 3,878>\mathrm{t}_{\text {table }} 1,974$ dan Sig $0,000<0,05$.

4. Kompensasi $\left(\mathrm{X}_{3}\right)$ Berengaruh Secara Parsial yang Positif Dan Signifikan Terhadap Semangat Kerja (Y). Hal ini ditunjukkan dengan nilai $t_{\text {hitung }} 2,991>$ $t_{\text {table }} 1,974$ dan Sig 0,003<0,0.

5. Gaya Kepemimpinan $\left(\mathrm{X}_{1}\right)$, Budaya Organisasi $\left(\mathrm{X}_{2}\right)$ dan Kompensasi $\left(\mathrm{X}_{3}\right)$ Berpengaruh Positif Dan Signifikan Secara Simultan Terhadap Semangat Kerja (Y). Hal ini ditunjukkan dengan nilai $F_{\text {hitung }} 63,567>F_{\text {tabel }} 2,66$ pada sig $\alpha 0,000<0.05$, hasil regresi linear berganda adalah $\mathrm{Y}=11,901+$ $0,085 \mathrm{X}_{1}+0,199 \mathrm{X}_{2}+0,173 \mathrm{X}_{3}$. Hal ini dapat disimpulkan bahwa variabel independen memiliki arah pengaruh positif terhadap semangat kerja pegawai.

B. Saran

Beberapa saran yang dapat diberikan dalam meningkatkan variabelvariabel yang di bahas dalam peneleitian ini, berikut saran yang dapat penulis berikan :

1. Pada instrumen Gaya kepemimpinan, instrumen ke 11 dengan skor terendah sebesar 511 dan rata-rata 3,01 dan masuk ke dalam rentang Cukup Baik, dalam meningkatkan peran kepemimpinan agar pimpinan bisa mengendalikan emosinya saat terjadi mis komunikasi kerja pada saat aktifitas kerja.

2. Pada instrumen Budaya Organisasi, instrumen ke 14 dengan skor terendah sebesar 445 dan skor rata- rata 2,62 dan masuk ke dalam kategori Cukup Baik, dalam agar karyawan lebih memahami budaya organisasi yang ada saat ini sehingga suasana kerja dapat lebih stabil, efektif dan efisien.

3. Pada instrumen Kompensasi, instrumen ke 1 dengan skor terendah sebesar 356 dan rata-rata 2,09 dan masuk ke dalam kategori Tidak Baik. Perusahaan agar mempertimbangkan kenaikan gaji dan upah yang sesuai kondisi perekonomian saat ini agar biaya hidup karyawan dan keluarganya dapat lebih terjamin.

4. Pada instrumen Semangat Kerja, instrumen ke 3 dengan skor terendah sebesar 444 dan rata-rata 2,61 dan masuk ke dalam kategori Cukup Baik. Perusahaan agar lebih mempertimbangkan kebijakan - kebijakan yang di buat oleh perusahaan agar menimbulkan kepuasan dan semangat kerja

\section{DAFTAR PUSTAKA}

Alwi, Syafarudin. 2008. Manajemen Sumber Daya Manusia. Edisi kedua. Yogyakarta: BPFE Yogyakarta

Ghozali. Imam. 2013 Aplikasi Analisis Multivariate dengan Program IBM SPSS. 20. Semarang: Badan Penerbit Universitas Diponegoro.

Handoko TH,. 2008. Manajemen Personalia dan Sumber Daya Manusia. Edisi 2. Yogyakarta: BPFE

Kreitner, Robert dan Kinicki, Angelo 2003. Perilaku Organisasi, Terjemahan: Erly Suandy, Edisi Pertama, Penerbit Salemba Empat, Jakarta.

Malayu S. P Hasibuan, 2013, Manajemen Sumber Daya Manusia. Edisi revisi Bumi Aksara, Jakarta : Grasindo 
Munandar, Ashar Sunyoto. 2008. Psikologi Industri dan Organisasi. Universitas. Indonesia, Jakarta

Ndraha, Taliziduhu. 2005. Budaya Organisasi. Cetakan Kedua. Jakarta: Rineka Cipta.

Pabundu Tika, 2012. Budaya Organisasi dan Peningkatan Kinerja Perusahaan. Jakarta:Bumi Aksara.

Kinerja Perusahaan, Cetakan ke-3. Jakarta : PT. Bumi Aksara

Rivai Veitzal., 2014, Manajemen Sumber Daya Manusia untuk Perusahaan Dari Teorike Praktek. PT Raja Grafindo Perkasa, Jakarta

Siregar, Syofian. 2014. Satatistik Parametrik Untuk Penelitian Kuantitatif, Jakarta. Penerbit : Bumi Aksara

Sugiyono, 2010, "Metode Penelitian Bisnis", Alfabeta Bandung

Suharsini Arikunto. 2010 "Prosedur Penelitian", Penerbit : Rineka Cipta, Jakarta. 